\title{
Effects of astragalosides from Radix Astragali on high glucose-induced proliferation and extracellular matrix accumulation in glomerular mesangial cells
}

\author{
XIAO $\mathrm{CHEN}^{1,2^{*}}$, DONG-DONG WANG ${ }^{1 *}$, TONG WEI ${ }^{1}$, SU-MEI HE $^{1}$, GUAN-YING ZHANG $^{1}$ and QUN-LI WEI ${ }^{1}$ \\ ${ }^{1}$ Jiangsu Key Laboratory of New Drug Research and Clinical Pharmacy, Xuzhou Medical College, Xuzhou, Jiangsu 221004; \\ ${ }^{2}$ Department of Pharmacy, The People's Hospital of Jiangyin, Jiangyin, Jiangsu 214400, P.R. China
}

Received January 30, 2015; Accepted March 8, 2016

DOI: $10.3892 /$ etm.2016.3194

\begin{abstract}
Diabetic nephropathy (DN) exhibits a deteriorating course that may lead to end-stage renal failure. Astragalosides have been clinically tested for the treatment of DN, but the mechanism is unclear at present. In this study, the effects of astragalosides were investigated on high glucose-induced proliferation and expression of transforming growth factor- $\beta_{1}$ (TGF- $\beta_{1}$ ), connective tissue growth factor (CTGF), type IV collagen (colIV) and fibronectin (FN) in glomerular mesangial cells (MCs). Cell proliferation was determined by 5-bromo-2'-deoxyuridine assay, and the expression of TGF- $\beta_{1}$, CTGF, colIV and FN mRNA and proteins in MCs was detected by reverse transcription-polymerase chain reaction and ELISA assay, respectively. The results showed that high glucose clearly induced the proliferation of MCs and increased the expression of TGF- $\beta_{1}, \mathrm{CTGF}$, colIV and FN. Treatment with $50,100,200 \mu \mathrm{g} / \mathrm{ml}$ astragalosides inhibited cell proliferation and the expression of TGF- $\beta_{1}, \mathrm{CTGF}$, colIV and FN induced by high glucose. Thus, it is concluded that astragalosides inhibit the increased cell proliferation and expression of major extracellular matrix proteins that are induced by high glucose, indicating their value for the prophylaxis and therapy of DN.
\end{abstract}

\section{Introduction}

The prevalence of diabetic nephropathy (DN) is increasing markedly worldwide, and DN is currently the most common cause of end-stage renal failure requiring renal replacement

Correspondence to: Professor Qun-Li Wei, Jiangsu Key Laboratory of New Drug Research and Clinical Pharmacy, Xuzhou Medical College, 209 Tongshan Road, Xuzhou, Jiangsu 221004, P.R. China

E-mail: weiqunli@126.com

*Contributed equally

Key words: astragalosides, diabetic nephropathy, mesangial cells, cell proliferation, extracellular matrix therapy $(1,2)$. The pathological features of DN include mesangial expansion, caused by the proliferation of mesangial cells and the excessive accumulation of extracellular matrix (ECM) $(3,4)$. Hyperglycemia has been demonstrated to be the main initiation factor in the etiology of DN (5). Hyperglycemia can activate multiple intracellular signaling factors, resulting in the accumulation of ECM (6-8). Among these factors, transforming growth factor (TGF)- $\beta_{1}$ and its downstream mediator connective tissue growth factor (CTGF) are recognized as fibrogenic cytokines and play a critical role in the kidney pathophysiology of DN $(9,10)$. Mesangial cells (MCs) are recognized as the major ECM-secreting cells $(11,12)$. The inhibition of MC proliferation and ECM accumulation should be beneficial in DN. The major ECM proteins include collagen IV (colIV) and fibronectin (FN) (13). Therefore, changes in the concentrations of colIV and FN can be used to study the pathological changes of DN $(14,15)$.

However, at present there is no treatment available that is able to arrest the progression of DN to end-stage renal failure, and new therapeutic strategies for the management of DN are therefore required (16). Chinese medical herbs are considered to be a promising source of potential treatments due to their variety of species and applications. Radix Astragali, the root of Astragalus membranaceus Bunge, is widely used in traditional Chinese medicine for its anti-inflammatory, anti-oxidative, immune-regulatory and neuroprotective activities $(17,18)$. The principle bioactive components extracted from Radix Astragali are known as astragalosides. A clinical trial has shown that astragalosides have a potential role in the treatment of DN (19). Moreover, the results of a recent study suggested that the intravenous infusion of astragalosides in healthy Chinese volunteers was safe and well tolerated (20), and astragalosides appear to be efficient and safe for use in the therapy of DN. Therefore, the aim of the present study was to investigate the mechanism underlying the effects of astragalosides in the treatment of DN.

\section{Materials and methods}

Materials. Astragalosides were purchased from Shanghai Yuanye Biotechnology Co., Ltd (Shanghai, China). Rat MCs (No. HBZT-1) were obtained from Wuhan Boster Biological 
Table I. Primer sequences for reverse transcription-polymerase chain reaction.

\begin{tabular}{lll}
\hline Gene name & \multicolumn{1}{c}{ Forward sequence (5' to 3') } & Reverse sequence (5' to 3') \\
\hline TGF- $\beta_{1}$ & ATGTGCAGGATAATTGCTGCC & TGGTGTTGTACAGGCTGAGG \\
CTGF & GCTAAGACCTGTGGAATGGGC & CTCAAAGATGTCATTGCCCCC \\
ColIV & TCGGCTATTCCTTCGTGATG & TCTCGCTTCTCTCTATGGTG \\
FN & GCGACTCTGACTGGCCTTAC' & CCGTGTAAGGGTCAAAGCAT \\
-actin & TCAGGTCATCACTATCGGCAAT & AAAGAAAGGGTGTAAAACGCA
\end{tabular}

TGF- $\beta_{1}$, transforming growth factor- $\beta_{1}$; CTGF, connective tissue growth factor; ColIV, collagen IV; FN, fibronectin.

Technology, Ltd. (Wuhan, China). 5-Bromo-2'-deoxyuridine (BrdU) kit was purchased from Beyotime Institute of Biotechnology (Shanghai, China). The TRIzol kit and cDNA reverse transcription kit were from Takara Bio, Inc. (Otsu, Japan). The rat TGF- $\beta_{1}$, CTGF, FN and colIV enzyme-linked immunosorbent assay (ELISA) kits were purchased from R\&D Systems, Inc. (Minneapolis, MN, USA).

Cell culture and treatment. MCs were cultured in Gibco Dulbecco's modified Eagle's medium (DMEM; Thermo Fisher Scientific, Inc., Waltham, MA, USA) that was supplemented with $100 \mu \mathrm{g} / \mathrm{ml}$ streptomycin, $100 \mathrm{U} / \mathrm{ml}$ penicillin (both purchased from Beyotime Institute of Biotechnology) and $10 \%$ (v/v) fetal bovine serum (Hangzhou Sijiqing Biological Engineering Materials Co., Ltd., Hangzhou, China). The cells were incubated at $37^{\circ} \mathrm{C}$ in a humidified atmosphere of $5 \% \mathrm{CO}_{2}$. During the experiments, the cells were first exposed to a normal concentration of glucose [5.56 mmol/1; normal glucose (NG) group] for $4 \mathrm{~h}$, and then treated with high glucose (HG group; $30 \mathrm{mmol} / \mathrm{l}$ glucose), high glucose with $50 \mu \mathrm{g} / \mathrm{ml}$ astragalosides (ATSL group), high glucose with $100 \mu \mathrm{g} / \mathrm{ml}$ astragalosides (ATSM group), and high glucose with $200 \mu \mathrm{g} / \mathrm{ml}$ astragalosides (ATSH group). Mannitol (MA group) was used as a control to rule out the effect of osmotic pressure. The cells were harvested for analysis after 24 and $48 \mathrm{~h}$ of treatment.

Cell proliferation assay. Cell proliferation was examined by BrdU assay. MCs were seeded into 96-well plates at a density of $1.0 \times 10^{6}$ per well. After 24 and $48 \mathrm{~h}$, BrdU solution was added and the MCs continued to be cultured for another $2 \mathrm{~h}$. Absorbance was read at $450 \mathrm{~nm}$ by visible spectrometry (CliniBio 128C; Biochrom, Ltd., Cambridge, UK).

Reverse transcription-polymerase chain reaction (RT-PCR). An RT-PCR procedure was performed to determine the relative mRNA quantities of TGF- $\beta_{1}$, CTGF, ColIV and FN in MCs. Total RNA was extracted from the MCs with TRIzol reagent according to the manufacturer's protocol. The total RNA $(0.5 \mu \mathrm{g})$ obtained was converted into cDNA using the RevertAid ${ }^{\mathrm{TM}}$ First Strand cDNA Synthesis kit with Random Hexamer primers (Thermo Fisher Scientific, Inc.). The upstream and downstream primers (Shanghai Sangon Biotech Co., Ltd., China) of these genes are shown in Table I. The reaction mixture was incubated at $48^{\circ} \mathrm{C}$ for $45 \mathrm{~min}$ for reverse transcription, and then underwent cycling. The cycling conditions of these genes were: Initial denaturation for $5 \mathrm{~min}$ at $94^{\circ} \mathrm{C}, 30$ cycles at $94^{\circ} \mathrm{C}$ for $30 \mathrm{sec}$, $60^{\circ} \mathrm{C}$ for $30 \mathrm{sec}, 72^{\circ} \mathrm{C}$ for $1 \mathrm{~min}$, and final elongation at $72^{\circ} \mathrm{C}$ for $7 \mathrm{~min}$. The RT-PCR products were separated by $2 \%$ agarose electrophoresis, and the band densities were analyzed using laser densitometry (Tanon-1600R; Tanon Science \& Technology Co., Ltd., Shanghai, China). The relative quantities of mRNA of these four genes in the MCs were represented by the ratio of the band density of objective gene relative to that of $\beta$-actin.

ELISA. Levels of TGF- $\beta_{1}, \mathrm{CTGF}, \mathrm{ColIV}$ and FN in the supernatants of the MCs were determined by ELISA. The MC culture medium was collected and centrifuged at 13,000 x g for $15 \mathrm{~min}$ to pelletize the debris. The levels of these four proteins were determined according to the kit manufacturer's protocol. The colorimetric reaction was measured at $450 \mathrm{~nm}$.

Statistical analysis. Data are expressed as the mean \pm standard deviation. Statistical analyses were performed using the paired t-test for the comparison of two groups and one-way analysis of variance with Dunnett's test for the comparison of multiple groups. A value of $\mathrm{P}<0.05$ was considered statistically significant.

\section{Results}

Effects of AST on MC proliferation. A BrdU assay was employed to evaluate the impact of AST on MC proliferation. As shown in Fig. 1, the proliferation of MCs was increased after 24 and $48 \mathrm{~h}$ in the presence of a high concentration of glucose (HG group vs. NG group, $\mathrm{P}<0.01)$. The cell proliferation rates in the ASTL, ASTM and ASTH groups were significantly lower than those in the HG group $(\mathrm{P}<0.05$ for ASTL; $\mathrm{P}<0.01$ for ASTM and ASTH). Cell viability in the MA group was almost identical to that in the NG group, indicating no evident impact of the osmotic pressure generated by high glucose. The above results indicate that the administration of AST significantly suppressed high glucose induced-MC proliferation.

Effects of AST on high glucose-induced TGF- $\beta_{1}, C T G F$, ColIV and FN mRNA expression. The RT-PCR detection results showed that the mRNA levels of TGF- $\beta_{1}$, CTGF, ColIV and $\mathrm{FN}$ in the $\mathrm{HG}$ group were elevated compared with those of the $\mathrm{NG}$ group $(\mathrm{P}<0.01)$. At $24 \mathrm{~h}$ (representative results, Fig. 2A), the TGF- $\beta_{1}$, CTGF and FN mRNA levels in the groups treated with 100 or $200 \mu \mathrm{g} / \mathrm{ml}$ AST were all lower than those of the HG group (Fig. 2B, C and E). The ColIV mRNA levels in the group treated with $50 \mu \mathrm{g} / \mathrm{ml}$ AST were also decreased compared with those in 

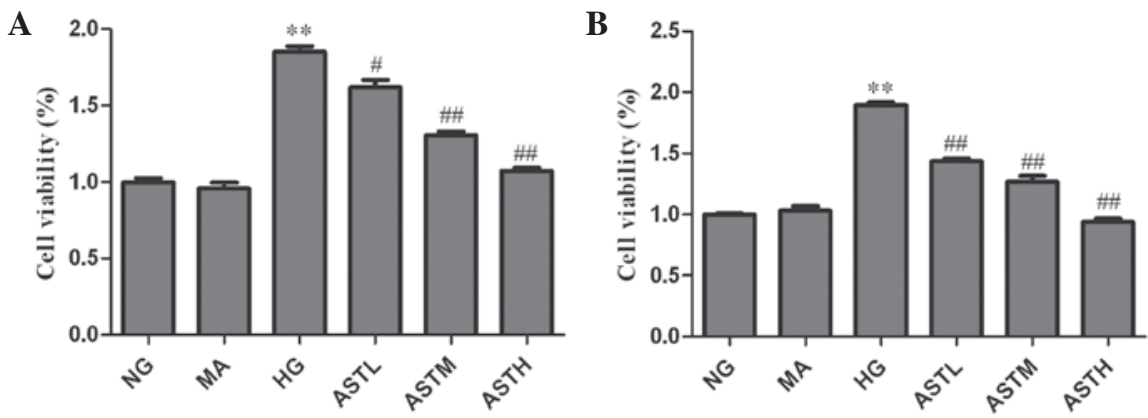

Figure 1. Cell proliferation rates in astragaloside (AST)-treated mesangial cells. Cell viability at (A) $24 \mathrm{~h}$ and (B) $48 \mathrm{~h}$. The cells were exposed to Dulbecco's modified Eagle's medium containing different substances, namely: $5.56 \mathrm{mmol} / \mathrm{l}$ glucose in the normal glucose (NG) group, $5.56 \mathrm{mmol} / 1 \mathrm{glucose}+24.44 \mathrm{mmol} / 1$ mannitol in the mannitol (MA) group, $30 \mathrm{mmol} / \mathrm{l}$ glucose in the high glucose (HG) group, $30 \mathrm{mmol} / \mathrm{l}$ glucose $+50 \mu \mathrm{g} / \mathrm{ml}$ AST in the low-dose AST (ASTL) group, $30 \mathrm{mmol} / \mathrm{l}$ glucose $+100 \mu \mathrm{g} / \mathrm{ml}$ AST in the medium-dose AST (ASTM) group, and $30 \mathrm{mmol} / 1 \mathrm{glucose}+200 \mu \mathrm{g} / \mathrm{ml}$ AST in the high-dose AST (ASTH) group. Values are presented as mean \pm standard deviation $(\mathrm{n}=3) .{ }^{* *} \mathrm{P}<0.01$ vs. the $\mathrm{NG}$ group; ${ }^{\sharp} \mathrm{P}<0.05,{ }^{\# \#} \mathrm{P}<0.01$ vs. the HG group.

A

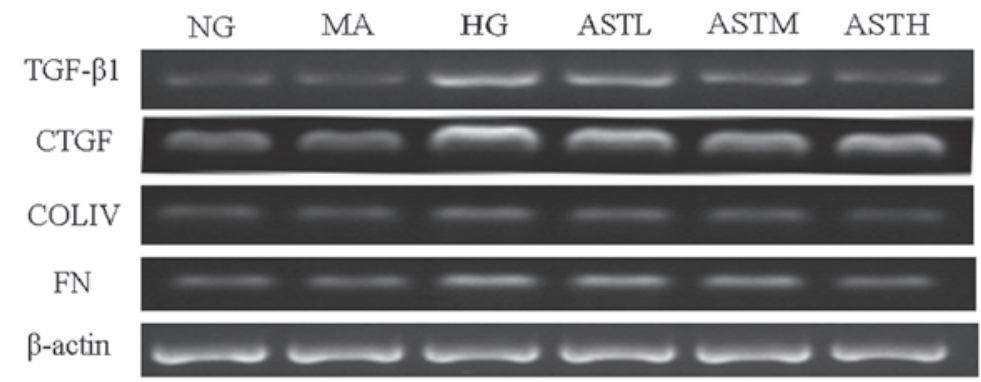

B

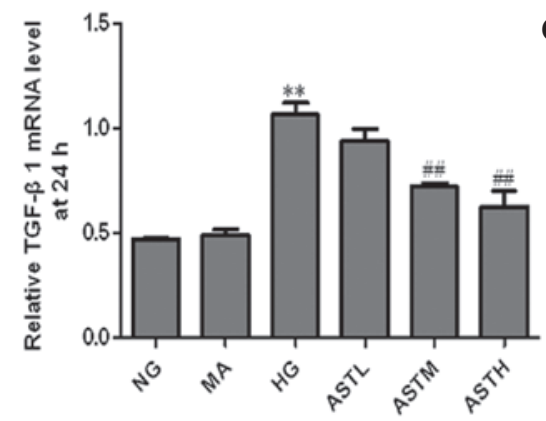

$\mathbf{D}$

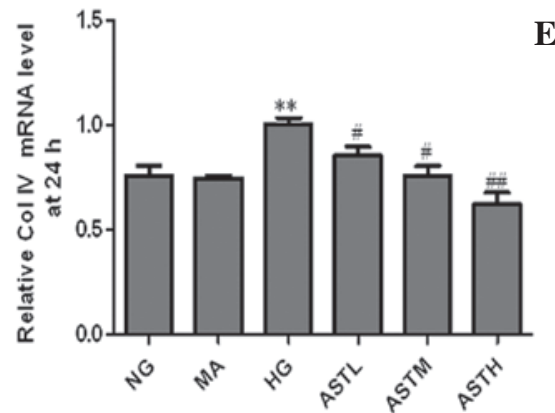

C

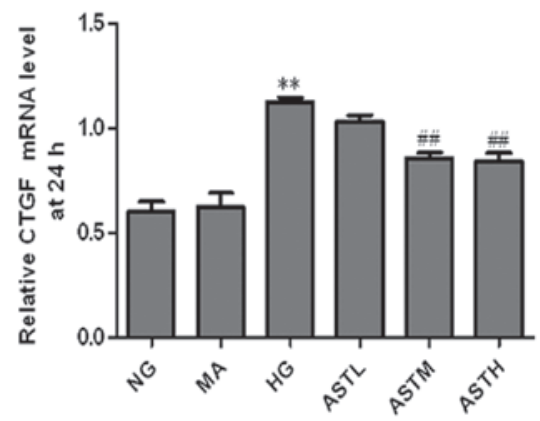

E

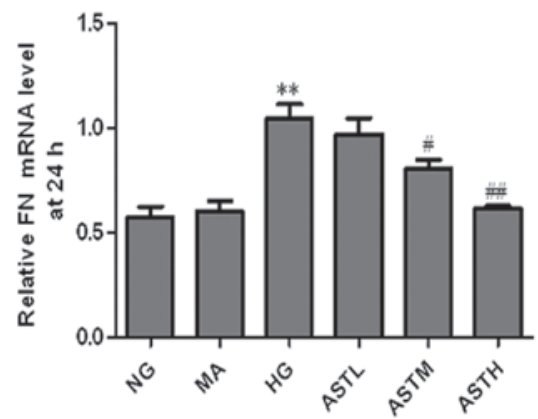

Figure 2. mRNA levels of TGF- $\beta 1$, CTGF, ColIV and FN in the astragaloside (AST)-treated mesangial cells at 24 h. (A) Agarose electrophoresis of reverse transcription polymerase chain reaction (RT-PCR) products amplified from the total RNA extracts of mesangial cells; $\beta$-actin was used as the internal standard in each sample. RT-PCR data for the relative mRNA quantities of (B) TGF- $\beta 1$, (C) CTGF, (D) ColIV and (E) FN determined by densitometric analysis. Values are presented as mean \pm standard deviation $(\mathrm{n}=3)$. ${ }^{* *} \mathrm{P}<0.01$ vs. the $\mathrm{NG}$ group; ${ }^{\#} \mathrm{P}<0.05$, ${ }^{\# \#} \mathrm{P}<0.01$ vs. the HG group. TGF, transforming growth factor; CTGF, connective tissue growth factor; ColIV, collagen IV; FN, fibronectin; NG, normal glucose, MA, mannitol; HG, high glucose; ASTL group, low-dose AST; ASTM, medium-dose AST; ASTH, high-dose AST.

the HG group (Fig. 2D). At $48 \mathrm{~h}$, the four types of mRNA in the ASTL, ASTM and ASTH groups were notably downregulated compared with those in the HG group (Fig. 3). No significant changes in the levels of TGF- $\beta_{1}$, CTGF, ColIV and FN mRNA were observed between the MA group and the NG group (Figs. 2 and 3). These results indicate that the administration of AST significantly decreased the high glucose-induced increases of TGF- $\beta_{1}$, CTGF, ColIV and FN mRNA levels. 
A

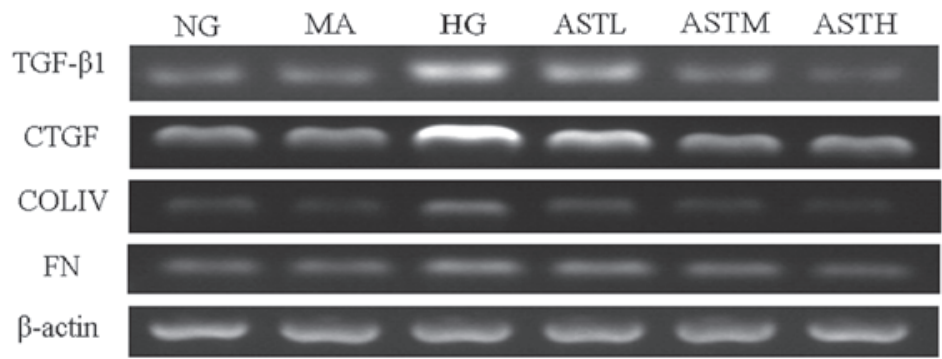

B

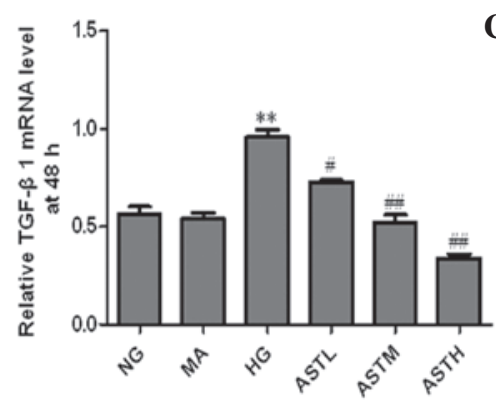

D

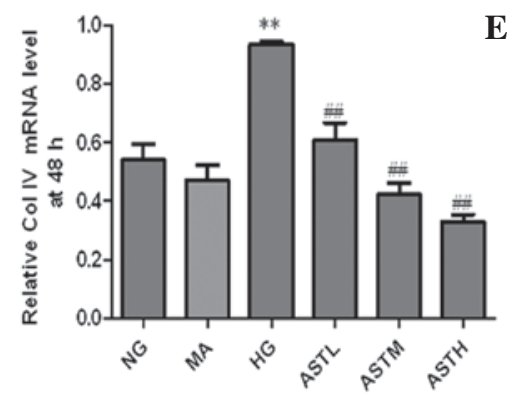

C

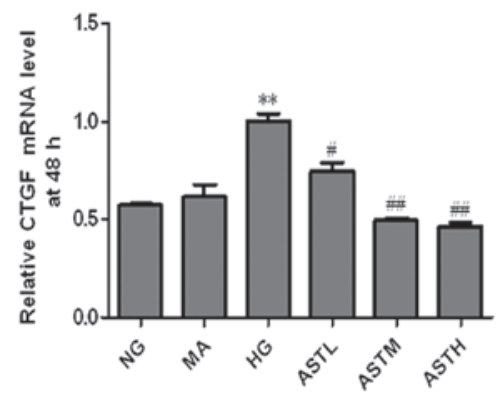

$\mathbf{E}$

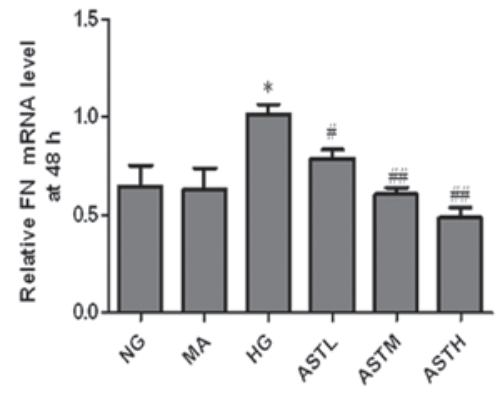

Figure 3. mRNA levels of TGF- $\beta 1$, CTGF, ColIV and FN in the astragaloside (AST)-treated mesangial cells at $48 \mathrm{~h}$. (A) Agarose electrophoresis of reverse transcription polymerase chain reaction (RT-PCR) products amplified from the total RNA extracts of mesangial cells; $\beta$-actin was used as the internal standard in each sample. RT-PCR data for the mRNA relative quantity of (B) TGF- $\beta 1$, (C) CTGF, (D) ColIV and (E) FN performed by densitometric analysis. Values are presented as mean \pm standard deviation, $\mathrm{n}=3$. ${ }^{*} \mathrm{P}<0.05,{ }^{* *} \mathrm{P}<0.01 \mathrm{vs}$. the NG group; ${ }^{*} \mathrm{P}<0.05,{ }^{\# \#} \mathrm{P}<0.01$ vs. the HG group. TGF, transforming growth factor; CTGF, connective tissue growth factor; ColIV, collagen IV; FN, fibronectin; FN, fibronectin; NG, normal glucose, MA, mannitol; HG, high glucose; ASTL group, low-dose AST; ASTM, medium-dose AST; ASTH, high-dose AST.

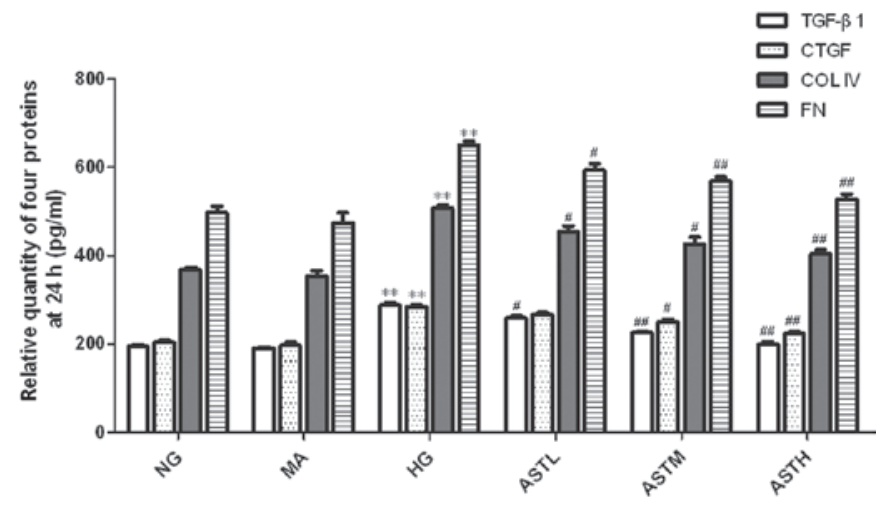

Figure 4. Relative quantity of TGF- $\beta 1$, CTGF, ColIV and FN proteins in the supernatant of astragaloside (AST)-treated mesangial cells at $24 \mathrm{~h}$. Values are presented as mean \pm standard deviation $(\mathrm{n}=3){ }^{* * *} \mathrm{P}<0.01$ vs. the $\mathrm{NG}$ group; ${ }^{\#} \mathrm{P}<0.05,{ }^{\# \#} \mathrm{P}<0.01$ vs. the HG group. TGF, transforming growth factor; CTGF, connective tissue growth factor; ColIV, collagen IV; FN, fibronectin; FN, fibronectin; NG, normal glucose, MA, mannitol; HG, high glucose; ASTL group, low-dose AST; ASTM, medium-dose AST; ASTH, high-dose AST.

Effect of AST on high glucose-induced regulation of TGF- $\beta_{1}$, $C T G F$, ColIV and FN. The levels of TGF- $\beta_{1}$, CTGF, ColIV and $\mathrm{FN}$ in the cell culture supernatants of the MCs in the $\mathrm{HG}$

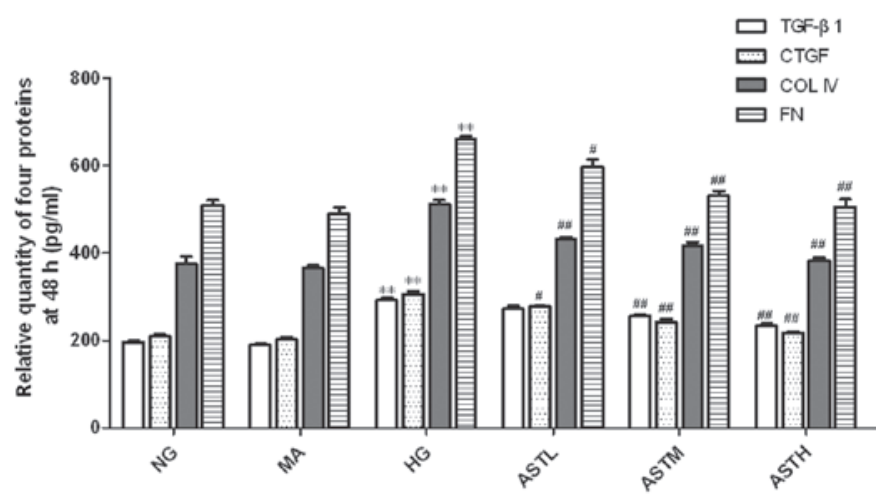

Figure 5. Relative quantity of TGF- $\beta 1$, CTGF, ColIV and FN proteins in the supernatant of astragaloside (AST)-treated mesangial cells at $48 \mathrm{~h}$. Values are presented as mean \pm standard deviation $(\mathrm{n}=3)$. ${ }^{* *} \mathrm{P}<0.01$ vs. the $\mathrm{NG}$ group; ${ }^{\#} \mathrm{P}<0.05,{ }^{\# \#} \mathrm{P}<0.01$ vs. the HG group. TGF, transforming growth factor; CTGF, connective tissue growth factor; ColIV, collagen IV; FN, fibronectin; FN, fibronectin; NG, normal glucose, MA, mannitol; HG, high glucose; ASTL group, low-dose AST; ASTM, medium-dose AST; ASTH, high-dose AST.

group were markedly upregulated compared with those of the NG group ( $\mathrm{P}<0.01$, Figs. 4 and 5). No significant difference between the NG group and the MA group was observed with 
regard to the secretion of these four proteins (Figs. 4 and 5). These results indicate that the administration of AST significantly reduced the high glucose-induced secretion of TGF- $\beta_{1}$, CTGF, ColIV and FN proteins.

\section{Discussion}

The pathological features of advanced DN include expansion of the mesangial ECM and thickening of the glomerular basement membrane (21). These pathological changes are caused by accumulation of ECM proteins and changes in the composition of these proteins (22). The accumulation of ECM in the mesangial area is generally associated with the deposition of FN and colIV (16). Therefore, reversing changes in FN and colIV synthesis might play a key role in delaying the progression of DN.

TGF- $\beta$ is a potent fibrogenic factor $(23,24)$. TGF- $\beta_{1}$ is highly expressed in the kidneys of diabetic animals (25) and humans (26) and contributes to the accumulation of ECM. CTGF, acting downstream of TGF- $\beta_{1}$, has been shown to mediate the expression of ECM proteins in response to various external perturbations $(27,28)$. Moreover, CTGF facilitates TGF- $\beta_{1}$ signaling and consequently promotes renal fibrosis (29). The coordinated expression of TGF- $\beta_{1}$ and CTGF appears to be crucial for the induction of ECM proteins and thus, for the development of DN (29).

The degree of ECM accumulation has been found to correlate with the extent of renal insufficiency and proteinuria (16), and MCs are recognized as being the major cells in the secretion ECM $(11,12)$. Therefore, the inhibition of MC proliferation and ECM accumulation should be beneficial in DN. In the present study it was found that astragalosides significantly suppressed high glucose induced-MC proliferation and decreased the high glucose-induced secretion of ColIV and FN proteins in vitro. Additionally, it was also found that astragalosides significantly suppressed the increases in the mRNA and protein expression levels of TGF- $\beta_{1}$ and CTGF that were induced by a high concentration of glucose.

In summary, astragalosides inhibited the accumulation of ColIV and FN, possibly through the downregulation of TGF- $\beta_{1}$-CTGF signaling, which provides a theoretical basis for their use in the treatment of DN.

\section{Acknowledgements}

This study was funded by the National Innovative Practice Training Program for Students of Higher Education Institutions (no. 201410313024) and the Innovative Practice Training Program for Students of Jiangsu Higher Education Institutions (no. 201410313024Z). This study was also funded by School of Pharmacy, Xuzhou Medical College Innovative Practice Training Program for Graduates (no. 2014YKYCX013).

\section{References}

1. Ritz E and Orth SR: Nephropathy in patients with type 2 diabetes mellitus. N Engl J Med 341: 1127-1133, 1999.

2. Remuzzi G, Schieppati A and Ruggenenti P: Clinical practice: Nephropathy in patients with type 2 diabetes. N Engl J Med 346: $1145-1151,2002$.
3. Kolset SO, Reinholt FP and Jenssen T: Diabetic nephropathy and extracellular matrix. J Histochem Cytochem 60: 976-986, 2012.

4. Tervaert TW, Mooyaart AL, Amann K, Cohen AH, Cook HT, Tervaert TW, Mooyaart AL, Amann K, Cohen AH, Cook HT, Drachenberg CB, Ferrario F, Fogo AB, Haas M, de Heer E, et al: Pathologic classification of diabetic nephropathy. J Am Soc Nephrol 21: 556-563, 2010.

5. Phillips CA and Molitch ME: The relationship between glucose control and the development and progression of diabetic nephropathy. Curr Diab Rep 2: 523-529, 2002.

6. Mishra R, Emancipator SN, Kern T and Simonson MS: High glucose evokes an intrinsic proapoptotic signaling pathway in mesangial cells. Kidney Int 67: 82-93, 2005.

7. Cooper ME: Interaction of metabolic and haemodynamic factors in mediating experimental diabetic nephropathy. Diabetologia 44: 1957-1972, 2001

8. Ha $\mathrm{H}$ and Lee HB: Reactive oxygen species as glucose signaling molecules in mesangial cells cultured under high glucose. Kidney Int Suppl 77: S19-S25, 2000.

9. Gao Q, Qin WS, Jia ZH, Zheng JM, Zeng CH, Li LS and Liu ZH: Rhein improves renal lesion and ameliorates dyslipidemia in $\mathrm{db} / \mathrm{db}$ mice with diabetic nephropathy. Planta Med 76: 27-33, 2010.

10. Brosius FC III: New insights into the mechanisms of fibrosis and sclerosis in diabetic nephropathy. Rev Endocr Metab Disord 9: 245-254, 2008.

11. Wang JY, Yin XX, Wu YM, Tang DQ, Gao YY, Wan MR, Hou XY and Zhang B: Ginkgo biloba extract suppresses hypertrophy and extracellular matrix accumulation in rat mesangial cells. Acta Pharmcol Sin 27: 1222-1230, 2006.

12. Lal MA, Brismar H, Eklöf AC and Aperia A: Role of oxidative stress in advanced glycation end product-induced mesangial cells activation. Kidney Int 61: 2006-2014, 2002.

13. Dronavalli S, Duka I and Bakris GL: The pathogenesis of diabetic nephropathy. Nat Clin Pract Endocrinol Metab 4: 444-452, 2008.

14. Wang JY, Yin XX, Wu YM, Tang DQ, Gao YY, Wan MR, Hou XY and Zhang B: Ginkgo biloba extract suppresses hypertrophy and extracellular matrix accumulation in rat mesangial cells. Acta Pharmacol Sin 27: 1222-1230, 2006.

15. Xu W, Shao X, Tian L, Gu L, Zhang M, Wang Q, Wu B, Wang L, Yao J, Xu X, et al: Astragaloside IV ameliorates renal fibrosis via the inhibition of mitogen-activated protein kinases and antiapoptosis in vivo and in vitro. J Pharmacol Exp Ther 350: 552-562, 2014.

16. Sato S, Kawamura H, Takemoto M, Maezawa Y, Fujimoto M, Shimoyama T, Koshizaka M, Tsurutani Y, Watanabe A, Ueda S, et al: Halofuginone prevents extracellular matrix deposition in diabetic nephropathy. Biochem Biophys Res Commun 379: 411-416, 2009.

17. Rios JL and Waterman PG: A review of the pharmacology and toxicology of Astragalus. Phytother Res 11: 411-418, 1997.

18. Liu G, Song J, Guo Y, Wang T and Zhou Z: Astragalus injection protects cerebral ischemic injury by inhibiting neuronal apoptosis and the expression of JNK3 after cerebral ischemic reperfusion in rats. Behav Brain Funct 9: 36, 2013.

19. Wei XP, Wu ZL and Wang JT: Clinical research on treating diabetes with Astragalus injection and TMP injection. Zhongguo Lin Chuang Yan Jiu 6: 14, 2014 (In Chinese)

20. Xu M, Yin J, Xie L, Zhang J, Zou C, Zou J, Liu F, Ju W and Li P: Pharmacokinetics and tolerance of total astragalosides after intravenous infusion of astragalosides injection in healthy Chinese volunteers. Phytomedicine 20: 1105-1111, 2013.

21. Mason RM and Wahab NA: Extracellular matrix metabolism in diabetic nephropathy. J Am Soc Nephrol 14: 1358-1373, 2003.

22. Nakajima T, Haseqawa G, Kamiuchi K, Fukui M, Yamasaki M, Tominaga $M$, Asano $M$, Hosoda $H$, Yoshikawa $T$ and Nakamura N: Differential regulation of intracellular redox state by extracellular matrix proteins in glomerular mesangial cells: Potential role in diabetic nephropathy. Redox Rep 11: 223-230, 2006

23. Sakharova OV, Taal MW and Brenner BM: Pathogenesis of diabetic nephropathy: Focus on transforming growth factor-beta and connective tissue growth factor. Curr Opin Nephrol Hypertens 10: 727-738, 2001.

24. Zhao TT, Zhang HJ, Lu XG, Huang XR, Zhang WK, Wang H, Lan HY and Li P: Chaihuang-Yishen granule inhibits diabetic kidney disease in rats through blocking TGF- $\beta / \mathrm{Smad} 3$ signaling. PLoS One 9: e90807, 2014. 
25. Sharma K and Ziyadeh FN: Renal hypertrophy is associated with upregulation of TGF-beta 1 gene expression in diabetic BB rat and NOD mouse. Am J Physiol 267: F1094-F1101, 1994.

26. Border WA and Noble NA: Evidence that TGF-beta should be a therapeutic target in diabetic nephropathy. Kidney Int 54: 1390-1391, 1998.

27. Liu X, Luo F, Pan K, Wu W and Chen H: High glucose upregulates connective tissue growth factor expression in human vascular smooth muscle cells. BMC Cell Biol 8: 1, 2007.
28. Guha M, Xu ZG, Tung D, Lanting L and Natarajan R: Specific down-regulation of connective tissue growth factor attenuates progression of nephropathy in mouse models of type 1 and type 2 diabetes. FASEB J 21: 3355-3368, 2007.

29. Qi W, Chen X, Poronnik P and Pollock CA: Transforming growth factor-beta/connective tissue growth factor axis in the kidney. Int J Biochem Cell Biol 40: 9-13, 2008. 